\title{
An inaugural diabetic ketoacidosis with acute pancreatitis during COVID-19
}

\author{
Clémence Tollard $^{1,2} \cdot$ Vanessa Champenois $^{3} \cdot$ Brigitte Delemer $^{2,4} \cdot$ Aline Carsin-V $^{5} \cdot$ Sara Barraud $^{2,4} \mathbb{C}$
}

Received: 25 August 2020 / Accepted: 14 October 2020 / Published online: 13 November 2020

(C) Springer-Verlag Italia S.r.l., part of Springer Nature 2020

Keywords Diabetes $\cdot$ COVID-19 $\cdot$ Ketoacidosis $\cdot$ Pancreas $\cdot$ SARS CoV-2 $\cdot$ Obesity

\section{Introduction}

A new viral infection (COVID-19) related to Severe Acute Respiratory Syndrome Coronavirus 2 (SARS-CoV-2) provoked a major public health crisis all around the world at the end of 2019.

Diabetes and obesity are described as risk factors for severe forms [1]. Besides the typical respiratory presentation, different organs impairments have been reported: digestive symptoms, multiple cases of neurological and/or cardiac manifestations. Accordingly, symptoms seem to be more diversified than initially expected.

It is through Angiotensin-Converting Enzyme 2(ACE2) that SARS-CoV-2 enter the host cells. This receptor is present in lungs, digestive tract, heart and brain. Additionally, ACE2 was also found in the pancreas, raising fears of pancreatic damages resulting from COVID-19 [2].

We aimed to describe the case of a French patient who developed an initial diabetic ketoacidosis followed by an acute pancreatitis with COVID-19.

Managed by Antonio Secchi.

Sara Barraud

sbarraud@chu-reims.fr

Clémence Tollard

ctollard@chu-reims.fr

Vanessa Champenois

vchampenois@chu-reims.fr

Brigitte Delemer

bdelemer@chu-reims.fr

Aline Carsin-Vu

acarsin-vu@chu-reims.fr

1 Université de Reims Champagne-Ardenne UFR de Médecine, 51 Rue Cognacq Jay, 51095 Reims Cedex, France

\section{Clinical case}

A 32-year-old female patient was hospitalized in emergency at the Reims University hospital in March 2020 for acute shortness of breath associated with a polyuria, polydipsia for several weeks. She had morbid obesity (BMI $40.4 \mathrm{~kg} /$ $\mathrm{m}^{2}$ ) and a first-degree family history of insulin-dependent diabetes.

She presented tachycardia, abdominal pain, polypnea without desaturation and fever (Table 1). She was agitated with a 15 Glasgow score. A severe diabetic ketoacidosis was present, with hyperleukocytosis, normal liver function and normal lipase level, as detailed in Table 1.

She was transferred to the intensive care unit for support with rehydration, IVSE insulin therapy (11 IU/h) and venous potassium supplementation. On day 2 , fever at $39.1{ }^{\circ} \mathrm{C}$ appeared with a dry cough, and persisting epigastric abdominal pain, despite the disappearance of ketoacidosis. Leukocytes were increased at $27 \mathrm{G} / \mathrm{L}$ with normal procalcitonin level. No bacterial infection was found, but SARS-CoV-2 polymerase chain reaction (PCR) on a nasopharyngeal swab was positive without other virus found in the multiplex PCR.

On day 4, she presented a brutal degradation with hypotension, enhanced epigastralgia and desaturation. Blood

2 Centre Hospitalier Universitaire de Reims, Service d'Endocrinologie - Diabète - Nutrition, Avenue du Général Koenig, 51092 Reims Cedex, France

3 Centre Hospitalier Universitaire de Reims, Service de Médecine Intensive et Réanimation Polyvalente, Avenue du Général Koenig, 51092 Reims Cedex, France

4 CRESTIC EA 3804, Université de Reims Champagne Ardenne, UFR Sciences Exactes et Naturelles, Moulin de La Housse, BP 1039, 51687 Reims Cedex 2, France

5 Centre Hospitalier Universitaire de Reims, Service de Radiologie, Avenue du Général Koenig, 51092 Reims Cedex, France 
Table 1 Patient's laboratory findings

\begin{tabular}{llll}
\hline & Admission & D4 & Range \\
\hline Respiratory rate & $30 / \mathrm{min}$ & $29 / \mathrm{min}$ & $10-16 / \mathrm{min}$ \\
Heart rate & $141 \mathrm{bpm}$ & $133 \mathrm{bpm}$ & $60-100 \mathrm{bpm}$ \\
Oxygen saturation & $100 \%$ & $97 \%$ & $95-100 \%$ \\
Blood pressure & $189 / 78 \mathrm{mmHg}$ & $91 / 46 \mathrm{mmHg}$ & $120 / 80 \mathrm{mmHg}$ \\
Temperature & $36.6^{\circ}$ & $38.6^{\circ}$ & $36^{\circ}-38^{\circ}$ \\
Blood glucose & $47.7 \mathrm{mmol} / \mathrm{L}$ & $7.1 \mathrm{mmol} / \mathrm{L}$ & $3.3-6 \mathrm{mmol} / \mathrm{L}$ \\
Ketonemia & $4.20 \mathrm{mmol} / \mathrm{L}$ & & $0-0.9 \mathrm{mmol} / \mathrm{L}$ \\
Sodium & $139 \mathrm{mmol} / \mathrm{L}$ & $149 \mathrm{mmol} / \mathrm{L}$ & $136-145 \mathrm{mmol} / \mathrm{L}$ \\
Potassium & $5.2 \mathrm{mmol} / \mathrm{L}$ & $3.3 \mathrm{mmol} / \mathrm{L}$ & $3.4-4.5 \mathrm{mmol} / \mathrm{L}$ \\
Leukocytosis & $14.9 \mathrm{G} / \mathrm{L}$ & $3.2 \mathrm{G} / \mathrm{L}$ & $4-10 \mathrm{G} / \mathrm{L}$ \\
Neutrophilic polynuclear & $10.9 \mathrm{G} / \mathrm{L}$ & $2.2 \mathrm{G} / \mathrm{L}$ & $2-7.5 \mathrm{G} / \mathrm{L}$ \\
Lymphocyte & $2.3 \mathrm{G} / \mathrm{L}$ & $0.8 \mathrm{G} / \mathrm{L}$ & $1-4 \mathrm{G} / \mathrm{L}$ \\
Eosinophilic polynuclear & $0 \mathrm{G} / \mathrm{L}$ & $0 \mathrm{G} / \mathrm{L}$ & $0.1-0.2 \mathrm{G} / \mathrm{L}$ \\
Lipase & $53 \mathrm{IU} / \mathrm{L}$ & $321 \mathrm{IU} / \mathrm{L}$ & $13-60 \mathrm{IU} / \mathrm{L}$ \\
$\mathrm{AST}$ & $23 \mathrm{IU} / \mathrm{L}$ & $8020 \mathrm{IU} / \mathrm{L}$ & $10-35 \mathrm{IU} / \mathrm{L}$ \\
$\mathrm{ALT}_{\mathrm{GGT}}$ & $18 \mathrm{IU} / \mathrm{L}$ & $2904 \mathrm{IU} / \mathrm{L}$ & $10-35 \mathrm{IU} / \mathrm{L}$ \\
$\mathrm{PT}_{\mathrm{pH}}$ & $18 \mathrm{IU} / \mathrm{L}$ & $155 \mathrm{IU} / \mathrm{L}$ & $5-36 \mathrm{IU} / \mathrm{L}$ \\
$\mathrm{P}_{\mathrm{a}}$ & $74 \%$ & $43 \%$ & $70-120$ \\
$\mathrm{PCO}_{2}$ & 7.01 & 7.46 & $7.35-7.45$ \\
$\mathrm{HCO}_{3}$ & $115 \mathrm{mmHg}$ & $85 \mathrm{mmHg}$ & $83-108 \mathrm{mmHg}$ \\
\hline
\end{tabular}

D4 = day 4, AST $=$ aspartate aminotransferase, $\mathrm{ALT}=$ alanine aminotransferase, $\mathrm{GGT}=$ Gamma-glutamyl transferase, $\mathrm{PT}=$ Prothrombin Time, $\mathrm{P}_{\mathrm{a}} \mathrm{O}_{2}=$ Oxygen partial pressure, $\mathrm{PCO}_{2}=$ Partial pressure of carbon dioxide, $\mathrm{HCO}_{3}=$ Bicarbonate of sodium test showed an inflammatory syndrome (procalcitonin at $33.99 \mu \mathrm{g} / \mathrm{L}$ ), an increased lipasemia and an altered liver functions associated with hepatocellular insufficiency (Factor V: 64\%) (Table 1).

The CT-scan showed typical pulmonary signs of SARSCoV-2 (lung involvement $>50 \%$ ), without associated pulmonary embolism and severe pancreatitis with a Computed Tomography Severity Index (CTSI) of 6 (Fig. 1).

The patient was then intubated and ventilated. Volume expander, vasoactive amines and broad-spectrum antibiotic therapy were administered. Insulin therapy was continued with IVSE with doses up to $30 \mathrm{UI} / \mathrm{h}$, without reaching normal glucose level.

The patient presented a rapid deterioration of clinical course, with a vasoplegic shock refractory to treatment, aggravation of hepatocellular insufficiency (11\% PT) and the appearance of disseminated intravascular coagulation (Factor V: 12\%, fibrinogen: $1.6 \mathrm{~g} / \mathrm{l}$, D-dimer: $17.67 \mathrm{ng} / \mathrm{l}$, Platelets: $23 \mathrm{G} / 1$ ). She died 7 days after her admission.

Regarding the etiological assessment of the acute pancreatitis, no alcohol consumption, biliary lithiasis on CT-scan, hypercalcemia or hypertriglyceridemia were found. No viral or autoimmune causes for hepatitis were noticed either. The postmortem liver biopsy did not show any SARS-CoV-2 in PCR or any indirect sign of viral infection. In addition, the diabetes assessment showed an $\mathrm{HbA} 1 \mathrm{C}$ of $13.1 \%$ (120 mmol/ mol IFCC), anti-glutamic acid decarboxylase (GAD) antibodies were negative and anti-islet antigen phosphatase (IA2) antibodies were positive $(17 \mathrm{IU} / \mathrm{L}$, normal range: $<10)$.

\section{Discussion}

This clinical case illustrates the damages made to two pancreatic cell lines (endocrine and exocrine) and the insulin resistance in the context of a SARS-CoV-2 infection, in patient with newly discovered diabetes.

Considering the viral infection, a fulminant diabetes could be hypothesized. However, the value of $\mathrm{HbA1c}$ and the increase IA2 antibodies is inconsistent with this diagnosis. The most likely etiology is type 1 diabetes, revealed by ketoacidosis, which was precipitated by SARS CoV-2. Nevertheless, this case remains atypical, with major initial hyperglycemia, unusual in type 1 diabetes and major insulin needs to control the metabolic disease. As suggested by Rubino et al., SARS-CoV-2 may have caused pleiotropic alteration of glucose metabolism [3].

Additionally, no common cause of pancreatitis has been found, including gallstones, alcohol misuse, hypercalcemia or hypertriglyceridemia. Rarer etiology of pancreatitis must be 

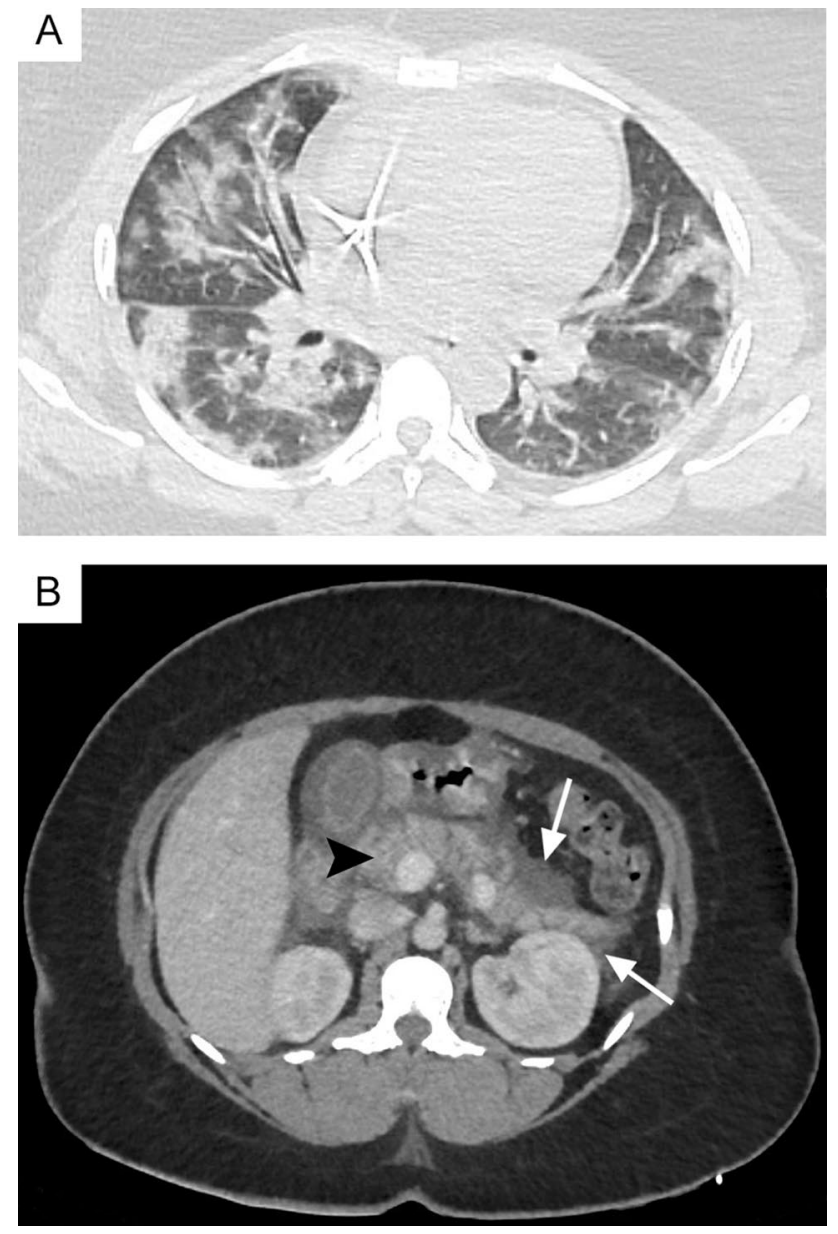

Fig. 1 Axial contrast-enhanced CT images 4 days after admission: a Lung CT image shows typical CT findings of SARS-CoV-2 with multiple ground-glass opacities and consolidations predominant at lung lower parts; and b abdominal CT image shows diffusely enlarged pancreas (black arrowhead), thickening of anterior left renal fascia and peripancreatic fat stranding (white arrows) consistent with acute pancreatitis

mentioned. First of all a pancreatitis may complicate DKA, but this is a rare phenomenon and associated with hypertriglyceridemia, which is absent in our case. Pancreatitis related to resuscitation in a context of hypoperfusion is also described. However, the patient had abdominal pain prior to collapse, and CT abnormalities were present immediately after the onset of hypotension. The main hypothesis seems therefore to be an exocrine pancreatic damage caused by the virus.

Other cases of ketoacidosis during COVID-19 have been reported in literature but no exocrine damage was described. A study on 658 patients found a ketosis in 42 patients among which 3 presented a ketoacidosis. Therefore, endocrine pancreatic damages, even if rare, could be associated with COVID-19 infections [4].

Besides, exocrine pancreatic damages related to COVID-19 have also been described by a Chinese team. The study included
67 patients with severe SARS-CoV-2 infections. Twelve patients presented an increased lipase and/or amylase levels associated in 5 patients with images of pancreatic abnormalities [2]. Furthermore, they also demonstrated that ACE2 were present in both pancreatic cell lines, and that mRNA level of ACE2 was higher in the pancreas than in the lung, in agreement with possible endocrine et exocrine pancreatic damages [2].

Finally, the death of this young healthy patient raises the question of the impact of obesity in the severity of the case. In fact, obesity leads to a dysregulation of the immune system and a chronic inflammatory reaction, reducing the body's defense capacities [5]. Hence, we can assume that clinical manifestations might have been worsened by obesity.

\section{Conclusion}

We report herein a first case of diabetic ketoacidosis associated with acute pancreatitis in a context of a severe COVID-19 and its fatal evolution, highlighting the hypothesis of pancreatic damages and alteration of glucose metabolism in the context of severe COVID-19 infections.

Acknowledgments Florence Bres, Maxime Hentzien, Firouze Bani-Sadr, Valette Charline and Sixtine Bousquet for her corrections.

\section{Compliance with ethical standards}

Conflict of interest The authors declare that they have no conflict of interest.

Ethical approval All procedures performed were in accordance with the ethical standards of the institutional committee and with the 1964 Helsinki declaration and its later amendments.

Informed consent Informed consent was obtained from the patient included in the case report.

\section{Reference}

1. Guan W, Ni Z, Hu Y et al (2020) Clinical characteristics of coronavirus disease 2019 in China. N Engl J Med 382(18):1702-1720. https://doi.org/10.1056/NEJMoa2002032

2. Liu F, Long X, Zhang B, Zhang W, Chen X, Zhang Z (2020) ACE2 expression in pancreas may cause pancreatic damage after SARSCoV-2 infection. Clin Gastroenterol Hepatol. 18(9):2128-2130. https://doi.org/10.1016/j.cgh.2020.04.040

3. Rubino F, Amiel SA, Zimmet P et al (2020) New-onset diabetes in Covid-19. N Engl J Med 383(8):789-790. https://doi.org/10.1056/ NEJMc2018688

4. Li J, Wang X, Chen J, Zuo X, Zhang H, Deng A (2020) COVID-19 infection may cause ketosis and ketoacidosis. Diabetes Obes Metab 22(10):1935-1941. https://doi.org/10.1111/dom.14057

5. Luzi L, Radaelli MG (2020) Influenza and obesity: its odd relationship and the lessons for COVID-19 pandemic. Acta Diabetol 57(6):759-764. https://doi.org/10.1007/s00592-020-01522-8

Publisher's Note Springer Nature remains neutral with regard to jurisdictional claims in published maps and institutional affiliations. 